\title{
EVALUATION OF DENSITIES OF WASTE MATERIALS IN TERMS OF THEIR UTILIZATION IN DENSE MEDIUM SEPARATIONS
}

\author{
${ }^{1}$ Filip KOVÁR, 'Lucie BARTOŇOVÁ \\ ${ }^{1}$ VSB - Technical University of Ostrava, Ostrava, Czech Republic, EU, \\ filip.kovar.st@vsb.cz, lucie.bartonova@vsb.cz
}

https://doi.org/10.37904/metal.2021.4088

\begin{abstract}
During last decades, extracting value-added products from industrial waste materials became a crucial research area because it not only provides valuable products but also mitigates the problem with disposal of these wastes and, at the same time, it facilitates saving natural resources. Various dense media for industrial separations are based on a variety of raw materials or commercially manufactured materials, such as clay, quartz, slate, galena, magnetite or ferrosilicon. Studies using industrial wastes for this purpose are very scarce and relate namely to zinc-lead waste or silicon-based waste; using such solids can provide required density but hinders the subsequent magnetic separation of the solid from the separation medium (which can be achieved if magnetic solid is used).

To address the aforementioned challenge, this study is focused to industrial materials produced in huge quantities (metallurgical wastes, power station ashes) and/or their fractions containing higher iron levels in order to find a suitable substituent for magnetite in terms of their utilization for dense medium (coal) cleaning applications. Particular attention is paid to evaluation of the density of these materials and/or their fractions, which predetermines their applications in dense medium separations.
\end{abstract}

Keywords: Material recovery of waste, coal, dense medium, density, magnetic separation

\section{INTRODUCTION}

Coal is one of the most important sources of energy in the world; it provides approximately $28 \%$ of the world's energy (BP Statistical Review of World Energy; 2017) [1]. The worldwide method for the treatment of coal as well as its enrichment is the separation of coal in a heavy suspension, the principle of which is based on the difference in density between coal and tailings enabling the separation of these materials.

The solid phase used for the suspension preparation should meet at least the following criteria: the solid particles must have at least twice the required density of the suspension, be insoluble in water and must not react with the raw material; the solid particles should be also resistant to abrasion, because an increase in the proportions of fine particles during the separation and regeneration of the suspension causes an increase in the viscosity of the separation medium. The suspension formed should exhibit a low viscosity, high stability and it must not be harmful to health [2,3]. The most widely used separation medium is a suspension of fine magnetite in water, a suspension of ferrosilicon or a mixture there of, based on the desired separation density. Density of heavy suspensions used for separation of coal (depending on the technology and the number of separation steps) falls within the range $1.25-2.0 \mathrm{~g} / \mathrm{cm}^{3}$ [2]. Using magnetite, the suspension reaches a density of up to $1.25-2.2 \mathrm{~g} / \mathrm{cm}^{3}$ and using ferrosilicon it is approximately $2.2-2.9 \mathrm{~g} / \mathrm{cm}^{3}$ depending on the technological requirements. To form a magnetite suspension, $500 \mathrm{~g}$ of fine magnetite $\left(5.0 \mathrm{~g} / \mathrm{cm}^{3}\right)$ per liter of suspension is used, which is a magnetite content of $10 \%$ by volume. (35 wt\%), the suspension density is $1.4 \mathrm{~g} / \mathrm{cm}^{3}$. The advantages of using magnetite include corrosion resistance and excellent magnetic regeneration [4]. 
Other less widely used high-density substances to produce heavy suspensions are, for example, silica sand $\left(2.65 \mathrm{~g} / \mathrm{cm}^{3}\right)$, barite $\left(4.5 \mathrm{~g} / \mathrm{cm}^{3}\right)$, pyrite $\left(5.0 \mathrm{~g} / \mathrm{cm}^{3}\right)$ or slate $\left(2.65 \mathrm{~g} / \mathrm{cm}^{3}\right)$ [5]. Silicon sand was used for the purpose of separation with particle size below $100 \mu \mathrm{m}$, but it is not used today. Barite has been used to prepare heavy suspensions so far, but its regeneration is difficult because barite cannot be magnetically regenerated [6]. Unlike barite or silica sand, regeneration of magnetite from the used suspension is very efficient; nevertheless, there is still some loss of material during regeneration. At present, the price of magnetite or other materials used for this purpose is very high and raw material stocks are gradually declining [7]; therefore, suitable substituents are intensively sought after.

At the same time, due to vast amount of industrial wastes produced annually all over the world, extracting value-added products out of these wastes is a global concern. It not only provides valuable products but also mitigates serious waste disposal problems and facilitates saving natural resources. To address the aforementioned challenges, this study is focused to industrial materials produced in huge quantities (metallurgical wastes, power station ashes) in order to find a suitable substituent for magnetite in terms of their utilization for dense medium (coal) cleaning applications. Attention is paid to evaluation of the density of these materials, which predetermines their applications in these (dense medium) separations.

\section{MATERIALS AND METHODS}

\subsection{Samples and analysis}

In order to find the wastes with suitable density (for dense medium separations), various industrial wastes materials were collected - coal combustion ashes from stoker power station and fluidised-bed power station and metallurgical wastes from various processes; for the comparison, two commercial magnetites were evaluated as well. Detailed description of the studied samples is summarized in Tables $\mathbf{1}$ and $\mathbf{2}$.

As power station ashes exhibit typically low densities, magnetic fractions were separated out of them manually by hand-held magnet, which is practical also with the view of the potential regeneration of the prepared suspension.

In order to evaluate the effect of particle size on the sample density, particle-size fractions were prepared by dry separation of $100 \mathrm{~g}$ of sample on sieves for 5 minutes. All samples were then dried at $105{ }^{\circ} \mathrm{C}$ for 2 hours according to the standard ISO 8833:1989 [8]. The densities of the samples were determined by helium pycnometry on Pycnomatic ATC (Thermo Scientific, USA) automatic pycnometer.

\subsection{Calculation of the solid concentration in suspension with required density}

The weight of solid phase $\left(m_{T}\right)$ required to obtain a heavy suspension of a given density and volume of water $\left(V_{K}\right)\left(\delta=1000 \mathrm{~kg} \cdot \mathrm{m}^{-3}\right)$ in this suspension can be calculated as [6]:

$m_{T}=\rho \cdot \frac{\delta_{S}-1000}{\rho-1000}$

$V_{K}=\frac{\rho-\delta_{S}}{\rho-1000}$

where:

$m_{T}$ - solid phase weight $(\mathrm{kg}), \delta_{S}$ - required suspension density $\left(\mathrm{kg} \cdot \mathrm{m}^{-3}\right), \rho$ - solid phase density $\left(\mathrm{kg} \cdot \mathrm{m}^{-3}\right)$ and $V_{K}$ - volume of liquid phase $\left(\mathrm{m}^{3}\right)$

The required volume concentration of the high density solid $(\varphi)$ and the volume of the solid phase $\left(V_{T}\right)$ to form the desired density of the suspension are calculated as: 
$V_{T}=\frac{m_{T}}{\rho}$

$V_{S}=V_{K}+V_{T}$

$\varphi=\frac{V_{T}}{V_{S}} \cdot 100$

where:

$V_{T}$ - solid phase volume $\left(\mathrm{m}^{3}\right), V_{S}$ - suspension volume $\left(\mathrm{m}^{3}\right)$ and $\varphi$ - volumetric concentration of high density solid (\%)

\section{RESULTS AND DISCUSSION}

\subsection{Densities of the studied waste materials}

Densities of metallurgical wastes are given in Table $\mathbf{1}$ and those of magnetic fractions prepared from coalcombustion power station ashes are given in Table 2.

Table 1 Densities of the metallurgical wastes and commercial magnetites

\begin{tabular}{|c|c|c|}
\hline Materials & $\begin{array}{c}\text { Particle-size fraction } \\
(\mathbf{m m})\end{array}$ & $\begin{array}{c}\text { Density } \\
\left(\mathbf{k g} \cdot \mathbf{m}^{-3}\right)\end{array}$ \\
\hline Steelworks discard & $<0.045$ & 2970 \\
\hline Steelworks discard & $0.045-0.053$ & 3010 \\
\hline Steelworks discard & $0.053-1.0$ & 4250 \\
\hline Steelworks discard, water leached & $0.053-1.0$ & 4370 \\
\hline Sinter dust, water leached & Bulk sample & 4090 \\
\hline Electric arc furnace dust & $<0.025$ & 4100 \\
\hline Electric arc furnace dust & $0.025-0.045$ & 4100 \\
\hline Electric arc furnace dust & $0.045-0.053$ & 4010 \\
\hline Electric arc furnace dust & $>0.053$ & 4050 \\
\hline Electric arc furnace dust, water leached & $0.045-0.053$ & 4240 \\
\hline Electric arc furnace dust, water leached & $>0.053$ & 4230 \\
\hline Steelworks dust slurry & Bulk sample & 4490 \\
\hline Scale & $<0.025$ & 5020 \\
\hline Scale & $0.025-0.045$ & 5010 \\
\hline Scale & $0.045-0.053$ & 5080 \\
\hline Scale & $>0.053$ & 5270 \\
\hline Scale, water leached & $0.045-0.053$ & 5090 \\
\hline Scale, water leached & $>0.053$ & 5300 \\
\hline Commercial magnetite & 0.01 & 5120 \\
\hline Commercial magnetite & 0.1 & 5130 \\
\hline
\end{tabular}

Table 2 Densities of the magnetic fractions from coal combustion power station ashes

\begin{tabular}{|c|c|c|}
\hline Materials & $\begin{array}{c}\text { Particle-size of magnetic fraction } \\
(\mathbf{m m})\end{array}$ & $\begin{array}{c}\text { Density } \\
\left(\mathbf{k g} \cdot \mathbf{m}^{-3}\right)\end{array}$ \\
\hline Bottom ash, stoker coal combustion plant & $0.2-0.6$ & 3350 \\
\hline Bottom ash, stoker coal combustion plant & $0.6-1.0$ & 3120 \\
\hline Fly ash, stoker coal combustion plant & $0.1-0.2$ & 3300 \\
\hline
\end{tabular}




\begin{tabular}{|c|c|c|}
\hline Fly ash, stoker coal combustion plant & $0.2-0.4$ & 3100 \\
\hline Bottom ash, fluidised-bed coal combustion plant & $0.2-0.4$ & 3130 \\
\hline
\end{tabular}

Densities of all magnetic fractions of coal combustion ash, regardless of the type of ash (fly ash and bottom ash), power plant or particle-size, are very low $\left(3100-3350 \mathrm{~kg} \cdot \mathrm{m}^{-3}\right)$ compared to commercial magnetites (5120 - $\left.5130 \mathrm{~kg} \cdot \mathrm{m}^{-3}\right)$. On the contrary, the densities of the metallurgical wastes are more suitable; with a few exceptions, they are mostly higher than $4000 \mathrm{~kg} \cdot \mathrm{m}^{-3}$ and the effect of the type of the metallurgical waste is more pronounced. The highest densities (similar to those of commercial magnetites) were observed for scale samples $\left(5020-5270 \mathrm{~kg} \cdot \mathrm{m}^{-3}\right)$; quite high values were obtained also for steelworks dust slurries $\left(4490 \mathrm{~kg} \cdot \mathrm{m}^{-3}\right)$ and electric arc furnace dusts $\left(4050-4100 \mathrm{~kg} \cdot \mathrm{m}^{-3}\right)$.

Unlike steelworks discard (that is rather heterogeneous), in case of electric arc furnace dust and scale samples, the effect of particle size on the density was quite low.

Leaching the samples in demineralized water did not bring about any significant change in density; the density of scale samples remained nearly unchanged, in case of steelworks discard $(0.053-1.0 \mathrm{~mm})$ the density increased only by $120 \mathrm{~kg} \cdot \mathrm{m}^{-3}$ and in case of the electric arc furnace dust samples $(>0.053$ and $0.045-0.053$ $\mathrm{mm}$ ) it increased by $180 \mathrm{~kg} \cdot \mathrm{m}^{-3}$ and $230 \mathrm{~kg} \cdot \mathrm{m}^{-3}$, respectively.

\subsection{Percentages of the high density solids in suspensions with required density}

The density of the solid materials is evaluated namely in relation to the percentage of this solid needed for the preparation of the dense medium suspension of the required density (that corresponds with the densities of the separated minerals, coal etc.) For easier evaluation, Figures 1-3 depict the relationships among the density of the solid, required final density of the suspension and the percentage of the solid needed for the preparation of such suspension. The studied solid materials were divided into three groups (three diagrams) according to their densities - Figure 1 evaluates all materials with the densities up to $3350 \mathrm{~kg} \cdot \mathrm{m}^{-3}$, Figure 2 depicts materials with the densities within the range of ca. $4000-4500 \mathrm{~kg} \cdot \mathrm{m}^{-3}$ and the materials with the highest densities $\left(>5000 \mathrm{~kg} \cdot \mathrm{m}^{-3}\right)$ are summarized in Figure 3.

In general, the lower is the density of the solid, the higher is the percentage needed for the preparation of the dense medium suspension. Nevertheless, the percentages of the solids cannot increase unlimitedly due to viscosity problems in case of higher concentrations. For example, if the suspension density of $2100 \mathrm{~kg} \cdot \mathrm{m}^{-3}$ is to be prepared, the volumetric concentration of the solid with the density of $3000-3350 \mathrm{~kg} \cdot \mathrm{m}^{-3}$ is ca. $45-55 \%$ (Figure 1) which could result in viscosity problems. If the density of the solid is ca. $4000-4500 \mathrm{~kg} \cdot \mathrm{m}^{-3}$, then the volumetric percentage $30-45 \%$ should be sufficient and in case of the magnetites of scales (with densities exceeding $5000 \mathrm{~kg} \cdot \mathrm{m}^{-3}$ ) only ca. $25-28 \%$ vol. can be used. Therefore, the magnetic fractions separated out of coal combustion ashes are not suitable for the preparation of the higher-density suspensions; nevertheless, they can be used for the preparation of the suspensions with lower densities. 


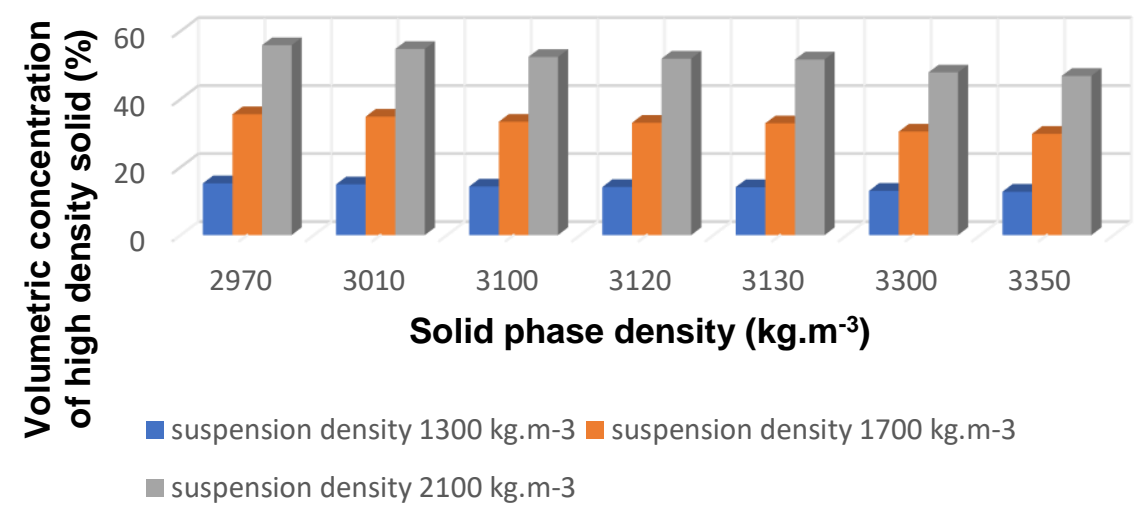

Figure 1 Percentages of the solid materials with the densities up to $3350 \mathrm{~kg} \cdot \mathrm{m}^{-3}$ needed for the preparation of the suspension of a model density of 1300,1700 and $2100 \mathrm{~kg} \cdot \mathrm{m}^{-3}$

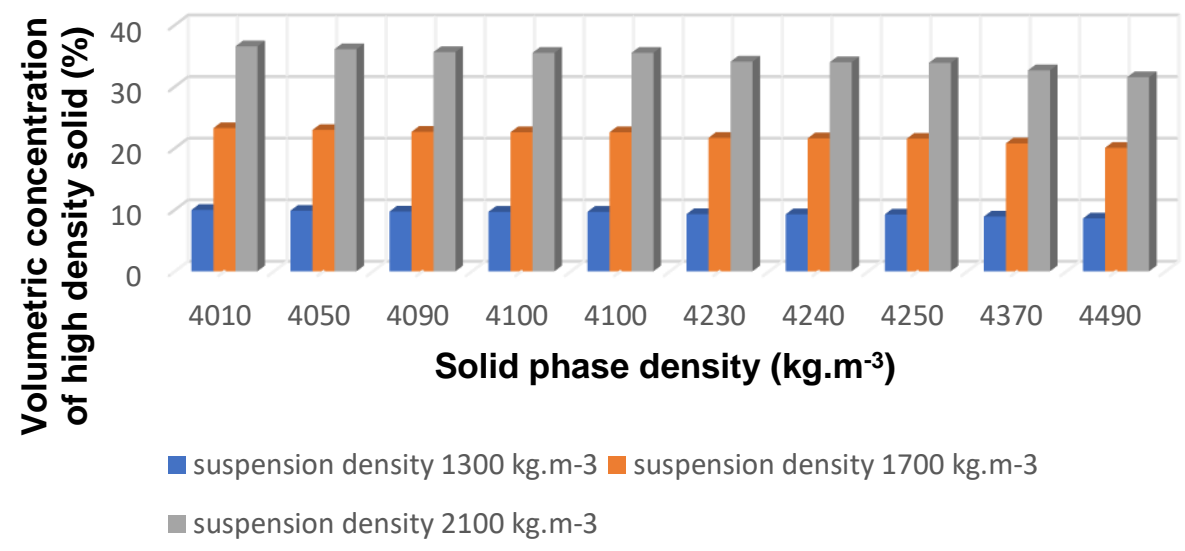

Figure 2 Percentages of the solid materials with the densities $4000-5000 \mathrm{~kg} \cdot \mathrm{m}^{-3}$ needed for the preparation of the suspension of a model density of 1300,1700 and $2100 \mathrm{~kg} \cdot \mathrm{m}^{-3}$

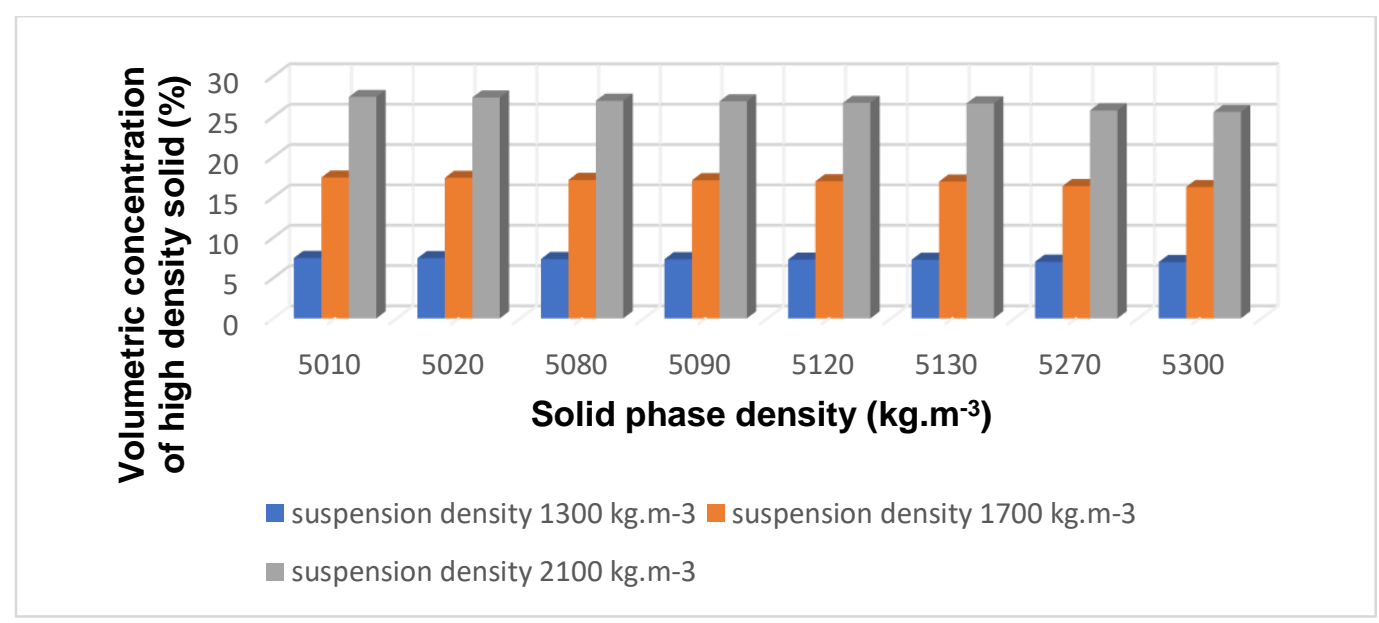

Figure 3 Percentages of the solid materials with the densities $>5000 \mathrm{~kg} \cdot \mathrm{m}^{-3}$ needed for the preparation of the suspension of a model density of 1300,1700 and $2100 \mathrm{~kg} \cdot \mathrm{m}^{-3}$ 


\section{CONCLUSION}

The main objective of this study was to find a suitable waste material as a potential substitute for magnetite, used as a solid phase for the preparation of heavy suspensions with the required density. Specifically, the study evaluates the densities of various waste materials from metallurgical industry and power stations.

The densities of the magnetic fractions of power-station ashes are quite low $\left(3100-3350 \mathrm{~kg} \cdot \mathrm{m}^{-3}\right)$ compared to commercial magnetite (ca. $5000 \mathrm{~kg} \cdot \mathrm{m}^{-3}$ ); hence, such solids cannot be used for the preparation of the suspensions with higher densities due to extremely high viscosities. Nevertheless, these magnetic fractions could be used for the preparation of suspensions in the density range of about $1200-1600 \mathrm{~kg} \cdot \mathrm{m}^{-3}$, where the volumetric concentration of the solid would not exceed $40 \%$. Moreover, the separation of the magnetic fractions out of power station ashes could be a promising way of decreasing iron content in ashes where higher iron levels hinder their further technological use (e.g., in another industrial branch).

In contrast, the density of scale $\left(5010-5300 \mathrm{~kg} \cdot \mathrm{m}^{-3}\right)$ is similar to that of magnetite $\left(\mathrm{ca} .5000 \mathrm{~kg} \cdot \mathrm{m}^{-3}\right)$ and it is high enough to be used for the production of the suspensions with higher densities.

Other investigated waste materials such as sinter dust, electric arc furnace dust and steelworks dust slurry exhibit a density falling within the range $4000-5000 \mathrm{~kg} \cdot \mathrm{m}^{-3}$, which could also be used for the preparation of higher-density suspensions.

The densities of the studied materials were not significantly affected by leaching in water, which is a promising observation in terms of their multiple use.

\section{ACKNOWLEDGEMENTS}

This work was supported by the Doctoral grant competition VSB - Technical University of Ostrava, reg. no. CZ.02.2.69/0.0/0.0/19_073/0016945 within the Operational Programme Research, Development and Education, under project DGS/TEAM/2020-014 "Material and energy recovery of waste" also results were accomplished by using Infrastructure ENREGAT under project No. LM2018098 and Student project No. SP2021/41.

\section{REFERENCES}

[1] BAHRAMI, A., GHORBANI, Y., MIROHAMMADI, M. et al. The beneficiation of tailing of coal preparation plant by heavy-medium cyclone. [online]. Int J Coal Sci Technol. 2018, vol. 5, pp. 374-384. Available from: https://doi.org/10.1007/s40789-018-0221-6.

[2] NOVÁČEK, Jiří. Technologie úpravy uhlí. Ostrava: VŠB-Technická univerzita, 2000.

[3] NAPIER-MUNN, T. J. The Effect of Dense Medium Viscosity on Separation Efficiency. Coal Preparation. [online]. 2007, vol. 8, pp. 145-165. Available from: https://doi.org/10.1080/07349349008905182.

[4] LASKOWSKI, J. S. Surface chemistry fundamentals in fine coal processing. The Coal Handbook: Towards Cleaner Production. Cambrige: Woodhead Publishing, 2013.

[5] AMINI, Sayed Hassan. Ultra clean coal production using dense medium separation for the silicon market. Kentucky, 2014. Thesis. University of Kentucky.

[6] BOTULA Jiří, VIDLÁŘ Jiří. Úprava nerostných surovin odpadů II [online]. 2018. [viewed: 2021-04-28]. Available from: https://www.vsb.cz/edudocs/files/0426ac85-fc18-44d0-b9d4-8847358a1b32

[7] PAVLÍK, R., ŘEPKA, V. Contribution to a Magnetite Consumption in the Karviná Mine's Preparation Plant of the Lazy Plant. GeoScience Engineering. [online]. 2012, vol. 58, pp. 1-6. Available from: https://doi.org/10.2478/gse2014-0035.

[8] ISO 8833:1989. Magnetite for use in coal preparation. Switzerland: International Organization for Standardization, 1989. 